Check for updates

Cite this: RSC Adv., 2018, 8, 29917

Received 24th May 2018

Accepted 17th August 2018

DOI: $10.1039 / \mathrm{c} 8 \mathrm{ra0} 4450 \mathrm{c}$

rsc.li/rsc-advances

\title{
Efficiency difference between furan- and thiophene-based D- $\pi-A$ dyes in DSSCs explained by theoretical calculations
}

\begin{abstract}
Xingyi Jin, ${ }^{\mathrm{a}}$ Libo Sun, ${ }^{\mathrm{a}}$ Dongyuan Li, ${ }^{\text {a }}$ Cheng-Long Wang ${ }^{\mathrm{b}}$ and Fu-Quan Bai (D) ${ }^{\mathrm{b}}$
The performance of two donor- $\pi$-bridge-acceptor type phenothiazine dyes bearing different $\pi$ bridges (furan and thiophene) was investigated by density functional theory and time-dependent density functional theory to explore the reasons for the differences in DSSC efficiency. It was revealed that dye1 with furan showed higher short-circuit photocurrent density due to its larger driving force and better light harvesting efficiency compared with dye2. Moreover, a larger number of photo-injected electrons into $\mathrm{TiO}_{2}$ for dye1 leads to higher open-circuit photovoltage. Our results indicate that furan could be used as a promising $\pi$-bridge to improve the efficiency of PTZ dyes. We hope that our work can provide a theoretical basis and view for designing efficient dyes in dye-sensitized solar cells (DSSCS).
\end{abstract}

\section{Introduction}

Dye-sensitized solar cells (DSSCs) have garnered considerable attention due to their great advantages, such as light weight, lowcost, and easy processing, as well as colorful and transparent features. ${ }^{1-3}$ As one of the crucial parts in dye-sensitized solar cells, the photosensitizers including ruthenium complexes, ${ }^{4-6}$ porphyrins, ${ }^{7}$ and metal-free organic dyes ${ }^{8-13}$ have been designed and applied to DSSCs in the past decades. Although an overall powerconversion efficiency above $11 \%$ has been established with ruthenium-based sensitizers, ${ }^{14}$ the limited resources and the environmental issues related to ruthenium use make it necessary to seek alternative dyes. Organic dyes are one of the most widely studied sensitizers for DSSCs because of their high extinction coefficients and environmental effects. ${ }^{15}$ However, the low conversion efficiency limits their practical application in our daily life. In recent years, much effort has been devoted to overcome this bottleneck..$^{16-19}$ Most of the reported organic dyes with high efficiencies depended on thiophene or thiophene-based heterocycles as the $\pi$-bridge, for example, coumarin-thiophene, ${ }^{20}$ carbazoleoligothiophene, ${ }^{21}$ and benzothiadizole-thiophene. ${ }^{22}$ These dyes show good stability because of the fact that holes in such dyes are located on the thiophene moieties. And furan, thiophene's oxygen analog, which has a high oxidation potential, would be more efficient for the holes location and reinforce the stability of the dye-

${ }^{a} 1^{\text {st }}$ Department of Neurosurgery, China-Japan Union Hospital, Jilin University, Xiantai Street No. 126, Changchun 130033, People's Republic of China. E-mail: dongyuan@ jlu.edu.cn

${ }^{b}$ Key Laboratory of Theoretical and Computational Chemistry, International Joint Research Laboratory of Nano-Micro Architecture Chemistry, Institute of Theoretical Chemistry, Jilin University, Changchun 130023, People's Republic of China sensitizers. ${ }^{21,23}$ However, furan has received much less attention compared to thiophene unit. Furan unit was incorporated into phenothiazine (PTZ) dye as an alternative to thiophene from 2011, showing better conversion efficiency than that containing thiophene unit. ${ }^{24}$ The similar experimental phenomena had also been reported by Hua $e t$ al. but again without deep understanding why the efficiency was improved. ${ }^{25}$ In current contribution, density functional theory (DFT) and time-dependent density functional theory (TD-DFT) were employed to explore the different performances of the dyes with respective furan and thiophene $\pi$-bridge. ${ }^{24}$ We hope the current contribution would provide theoretical guidance on optimizing the efficiency of existing donor- $\pi$ bridgeacceptor $(\mathrm{D}-\pi-\mathrm{A})$ dyes or even designing new $\mathrm{D}-\pi-\mathrm{A}$ dyes with better conversion efficiency.

\section{Theoretical background}

The overall conversion efficiency $\eta$ of solar cells is determined by the short-circuit photocurrent density $J_{\mathrm{sc}}$, the open-circuit photovoltage $V_{\mathrm{oc}}$, the fill factor $\mathrm{FF}$, and the intensity of the solar power $P_{\text {in }}$ :

$$
\eta=\mathrm{FF} \frac{V_{\mathrm{oc}} J_{\mathrm{sc}}}{P_{\mathrm{in}}}
$$

In DSSCs, the $J_{\mathrm{sc}}$ is determined by the following equation: ${ }^{26}$

$$
J_{\mathrm{sc}}=\int \operatorname{LHE}(\lambda) \Phi_{\mathrm{inj}}(\lambda) \eta_{\mathrm{coll}}(\lambda) \mathrm{d} \lambda
$$

- $\operatorname{LHE}(\lambda)$, the light harvesting efficiency (LHE) at the given wave-length $\lambda$; 
- $\Phi_{\text {inj }}(\lambda)$, the electron injection efficiency at the given wavelength;

- $\eta_{\text {coll }}(\lambda)$, electron collection efficiency on the interface between dye and the semiconductor at the given wave-length.

In the similar DSSCs systems with only one difference part in the $\pi$-bridge fragment of the sensitizer, $\eta_{\text {coll }}(\lambda)$ could be assumed to be a constant due to the similar structure of the dye-semiconductor interface. As a result, for the enhancement of $J_{\mathrm{sc}}$ the strategy of research should focus on improving LHE and $\Phi_{\text {inj. }}$. The light harvesting efficiency of the dye in the whole UV-vis range could be evaluated by calculating the area of the absorption bands. Obviously, the larger area of the absorption bands, the better for the short-circuit photocurrent density. In principle, to make the electron transfer energetically, on the one hand, the redox potential of the dye in the excited state, $E^{\text {dye* }}$, should be higher than conduction band of the semiconductor; on the other hand, the energetics of the excited states should be high enough to provide a thermodynamic driving force $\left(D_{\mathrm{f}}\right)$ for charge injection, assuming injection takes place at or near the Frank-Condon region. Furthermore, we made the approximation that the energetics of the dye are not different whether it is in $\mathrm{CH}_{2} \mathrm{Cl}_{2}$ solution or attached to $\mathrm{TiO}_{2}$ film, which is supported by previous studies performed by Kuciauskas. ${ }^{27,28}$ The driving force, $D_{\mathrm{f}}$, can be expressed $\mathrm{as}^{29,30}$

$$
D_{\mathrm{f}}=E^{\text {dye* }}-E_{\mathrm{CB}}=E_{\mathrm{dye}}+\lambda_{\max }-E_{\mathrm{CB}}
$$

- $E^{\mathrm{dye}}$, the redox potential of the excited dye;

- $E_{\text {dye }}$, the redox potential of dye in ground state;

- $\lambda_{\max }$, the largest vertical transition energy;

- $E_{\mathrm{CB}}$, the conduction band edge of the semiconductor, which is sensitive to the conditions, and the experimental value $-4.00 \mathrm{eV}$ ( $v s$. vacuum) is used widely. ${ }^{31}$

The DSSCs open-circuit photovoltage $V_{\mathrm{oc}}$ is the difference of electronic potential between the quasi-Fermi level of the semiconductor under illumination and the redox potential of the electrolyte. We can calculate the $V_{\mathrm{oc}}$ as: ${ }^{32}$

$$
V_{\text {oc }}=\frac{E_{\mathrm{C}}+\Delta \mathrm{CB}}{q}+\frac{k T}{q} \ln \left(\frac{n_{\mathrm{c}}}{N_{\mathrm{CB}}}\right)-\frac{E_{\text {readox }}}{q}
$$

where $q$ is the unit charge, $E_{\mathrm{c}}$ is the conduction band edge (CBE) of the semiconductor substrate, $T$ is the absolute temperature, $k$ is the Boltzmann constant, $n_{\mathrm{c}}$ is the number of electrons in the conduction band, $N_{\mathrm{CB}}$ is the density of accessible states in the conduction band, $E_{\text {readox }}$ is the reduction-oxidation potential of electrolyte, $\Delta \mathrm{CB}$ is the shift of the $E_{\mathrm{c}}$ when the dyes are adsorbed on substrate and can be expressed as: $:^{33}$

$$
\Delta \mathrm{CB}=\frac{q \mu_{\text {normal }} \gamma}{\varepsilon_{0} \varepsilon}
$$

here $q$ is electron charge, $\gamma$ is the dye's surface concentration, $\mu_{\text {normal }}$ is the dipole moment of individual dye molecules perpendicular to the surface of the semiconductor substrate, $\varepsilon_{0}$ and $\varepsilon$ represent the vacuum permittivity and the dielectric permittivity, respectively. According to eqn (4) and (5), it is obvious that $n_{\mathrm{c}}$ and $\mu_{\text {normal }}$ exert crucial influences on $V_{\mathrm{oc}}$.

\section{Computational details}

The ground state of the isolated dyes was optimized at B3LYP/ 6-31G(d $)^{34}$ level of theory in gas phase. Frequency calculations were performed at the same level of theory as the geometry optimizations to ensure that the ground state geometry corresponds to a minimum point on the potential energy surface. For TD-DFT calculations of isolated organic dyes in $\mathrm{CH}_{2} \mathrm{Cl}_{2}$, we evaluated several functional, including B3LYP, ${ }^{34}$ CAM-B3LYP, ${ }^{35}$ PBE0, ${ }^{36,37}$ BHandHLYP, ${ }^{38}$ and M062X, ${ }^{39}$ to screen out a proper exchange-correlation functional for current study. The conductor-like polarizable continuum model (C-PCM) was considered to simulate the solvent effects of dichloromethane. The results in Table 1 given by TDM062X/6-31G(d) were in good agreement with the experimental values in terms of transition energies. ${ }^{24}$ The absorption spectra were afterwards simulated by using Gaussian function with full-width at half-maximum (FWHM) of $0.3 \mathrm{eV}$. The oxidation potential of the ground state was calculated by B3LYP/UB3LYP/6-31G(d) level of theory according to the BornHaber cycle. ${ }^{28}$ For geometry optimization of $\mathrm{TiO}_{2}$ cluster and dye/ $/ \mathrm{TiO}_{2}$ complexes, plane-wave DFT calculations were performed using projector augmented wave (PAW) pseudopotentials as implemented in the VASP package. ${ }^{39,40}$ These calculations were carried by using generalized gradient approximation (GGA) of Perdew-Burke-Ernzerhof ${ }^{41}$ to account for the exchange-correlation effects. After optimization, the adsorption energies $\left(E_{\text {ads }}\right)$ of dyes on $\mathrm{TiO}_{2}$ surface were calculated with the following equation:

$$
E_{\mathrm{ads}}=E_{\mathrm{dye}}+E_{\mathrm{TiO}_{2}}-E_{\mathrm{dye}+\mathrm{TiO}_{2}}
$$

Here $E_{\text {dye }}$ denotes the total energy of isolated dye, $E_{\mathrm{TiO}_{2}}$ represents the total energy of $\mathrm{TiO}_{2}$ cluster, and $E_{\mathrm{dye}+\mathrm{TiO}}$ denotes the total energy of dye/ $/ \mathrm{TiO}_{2}$ complex. The frontier molecular orbitals (FMO) analysis of the dye $/ \mathrm{TiO}_{2}$ were performed under PBE0 level, and the natural population analysis (NPA) was carried out at M062X for ground state and TDM062X for excited state to evaluate the number of photoinjected electrons $(\Delta q)$. The dipole moments of free dyes were obtained at the geometry of the dyes bound to $\mathrm{TiO}_{2}$ cluster under the C-PCM-B3LYP level. The 6-31G(d) for nonmetal atoms and LanL2DZ basis set for Ti atoms have been selected for all the calculations for dye/ $/ \mathrm{TiO}_{2}$ complexes. The calculations of the geometry optimizations of dye/ $/ \mathrm{TiO}_{2}$ complexes and $\mathrm{TiO}_{2}$ cluster were in VASP, and the others were performed with Gaussian 09 program package. ${ }^{42}$

Table 1 Absorption peak comparison between experimental value $\lambda_{\max }$ and calculated $\lambda_{\max }$ under TD-DFT/6-31G* with $\mathrm{PCM}\left(\mathrm{CH}_{2} \mathrm{Cl}_{2}\right)$ level of theory

\begin{tabular}{lllllll}
\hline Functional & B3LYP & CAM-B3LYP & PBE0 & BHandHLYP & M062X & Exp $^{24}$ \\
\hline$\lambda_{\max } /(\mathrm{nm})$ & 534 & 415 & 503 & 414 & 420 & 442 \\
$f$ & 0.569 & 1.292 & 0.685 & 1.296 & 1.222 &
\end{tabular}




\section{Results and discussion}

\section{The effect of different $\pi$-bridge on isolated dyes}

To the dye molecules used in DSSCs, it is desirable to ensure that there exists a strong charge transport property and the electrons can be successively transferred to $\mathrm{TiO}_{2}$ along $\mathrm{D}-\pi-\mathrm{A}$ direction. From the perspective of molecular structure, the dye molecules need to be a flat structure and have small distances between adjacent parts. The optimized ground-state geometries of the dye 1 and dye 2 are displayed in Fig. 1, and the important geometrical parameters are collected in Table 2. The dyes are constructed by phenothiazine donor moiety (D), furan or thiophene as $\pi$-bridge $(\pi)$ and cyanoacrylic acid acceptor part (A).

In the $\mathrm{D}-\pi$-A dyes, the $\pi$-bridge is expected to function as the bridge of intramolecular charge transfer (ICT). ${ }^{\mathbf{4 3 4 4}}$ Therefore, the bridge bond between $\mathrm{D}$ and $\pi$-bridge or $\pi$-bridge and $\mathrm{A}$ has important effects on ICT. Herein, the bridge bonds between $\mathrm{D}$ and $\pi$-bridge, and $\pi$-bridge and A were marked as D- $\pi$ and $\pi$ $A$, respectively. The shorter length of bridge bonds is more beneficial for ICT in the $\mathrm{D}-\pi-\mathrm{A}$ dyes. As shown in Table 2 , the values of $\mathrm{D}-\pi$ bond lengths of dye1 and dye2 are 1.451 and $1.461 \AA$, respectively, which implies the intensity of interaction between PTZ and $\pi$-bridge is in the order of furan $>$ thiophene. On the other hand, the $\pi-\mathrm{A}$ bond lengths of dye 1 and dye 2 are 1.416 and $1.426 \AA$, which indicates that interaction of furan- $A$ is stronger than that of thiophene-A. For dye2, the dihedral angle between donor and $\pi$-bridge was calculated to be $22.3^{\circ}$, and it becomes $0.2^{\circ}$ in dye1. For these two dyes, the acceptor groups (A) were nearly coplanar with the $\pi$-bridge groups $(\pi)$ as $\pi-\mathrm{A}$ dihedral angles were calculated to be $0.1^{\circ}$ and $0.9^{\circ}$ for dye1 and dye2, respectively. Considering above, dye1 may be more beneficial for ICT due to its shorter bridge bond lengths and flatter conjugated structure.

One of the important requirements for improving the efficiencies of dyes is to extend the cover of the absorption spectra. The calculated absorption spectra of both dyes are shown in
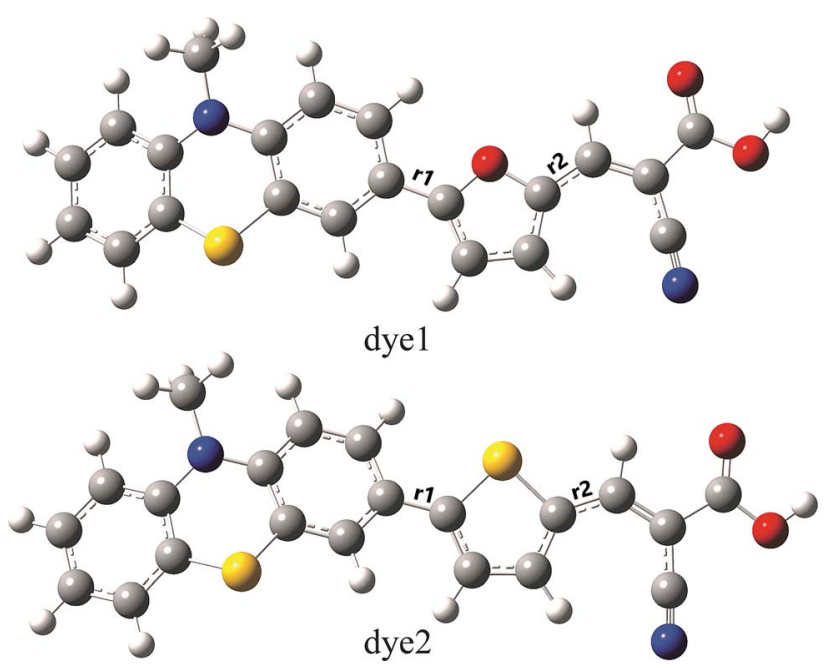

Fig. 1 Optimized ground-state geometries with tagged bond lengths of dye1 and dye2 ( $\mathrm{C}$ atom in grey; $\mathrm{H}$ atom in white; $\mathrm{O}$ atom in red; $\mathrm{S}$ atom in yellow; $\mathrm{N}$ atom in blue).
Table 2 The selected bond lengths ( $r_{1}$ and $r_{2}$ are marked out in Fig. 1) in angstroms and dihedral angles $(\Phi)$ in degrees of dye1 and dye2 (D: donor; $\pi$ : $\pi$-bridge; $\mathrm{A}$ : acceptor)

\begin{tabular}{llrlll}
\hline & $\mathrm{D}-\pi$ & & & $\pi-\mathrm{A}$ & \\
\cline { 2 - 3 } Molecule & $r_{1}$ & $\Phi$ & & $r_{2}$ & $\Phi$ \\
\hline dye1 & 1.451 & 0.2 & & 1.416 & 0.1 \\
dye2 & 1.461 & 22.3 & 1.426 & 0.9 \\
& & & & &
\end{tabular}

Fig. 2, and the corresponding data is summarized in Table 3. The results are in agreement with experimental measurement and this method is best for simulating the absorption spectra in our calculations. Both of dyes evidently exhibit major absorption bands in the $420 \mathrm{~nm}$ region. Markedly, the absorption intensity of dye1 is higher a bit than the dye2. All the absorption peaks are contributed from the HOMO to LUMO or HOMO - 1 to LUMO transitions with the $\mathrm{D}-\pi-\mathrm{A}$ direction. The integral area of the absorption bands for dye1 and dye 2 are 128 and 117, respectively, revealing that dye1 has better LHE to dye 2 over the almost same absorption region. Therefore, it can illustrate that the modification of $\pi$-bridge, by replacing thiophene with furan, has gradually enhancing effect in light harvesting efficiency (LHE).

Rapid and efficient electron injection after photo-excitation is also very important for improving the efficiency of the cell. Thereupon, the driving force $\left(D_{\mathrm{f}}\right)$ was also studied in detail. The calculated $D_{\mathrm{f}}$ as well as $E_{\text {dye }}$ and $E^{\text {dye* }}$ for both PTZ dyes are listed in Table 4 . It can be found that electron injection efficiency $\left(\Phi_{\mathrm{inj}}\right)$ increases along with higher $E^{\text {dye* }}$ and larger $D_{\mathrm{f}}$ in dye1 in contrast to dye2, thus indicating that the injection of the electron from excited state of dye1 to the $\mathrm{TiO}_{2}$ is much easier than dye2. Notably, the change of thiophene to furan improved the LHE but also shifts the $D_{\mathrm{f}}$ by $0.20 \mathrm{eV}$. Hence, considering the improved LHE and $\Phi_{\text {inj }}$, it can be expected that the DSSCs based on dye 1 should have minute intrinsic enhanced $J_{\text {sc }}$ than dye2, and that is also reflected in the experimental results $(12.18 v s$. $12.05 \mathrm{~mA} \mathrm{~cm}^{-2}$ in $J_{\mathrm{sc}}$ measurement). ${ }^{24}$ These tiny changes have also recently been captured by experimental scientists and used in the design of more new D- $\pi$-A dye molecules, ${ }^{45,46}$ and now we have a clear theoretical cognition.

\section{The effect of different $\pi$-bridge on dye- $\mathrm{TiO}_{2}$ complexes}

The anatase (101) surface is the most active surface since it has unpassivated $\mathrm{Ti}$ and $\mathrm{O}$ atoms, which has been widely used to
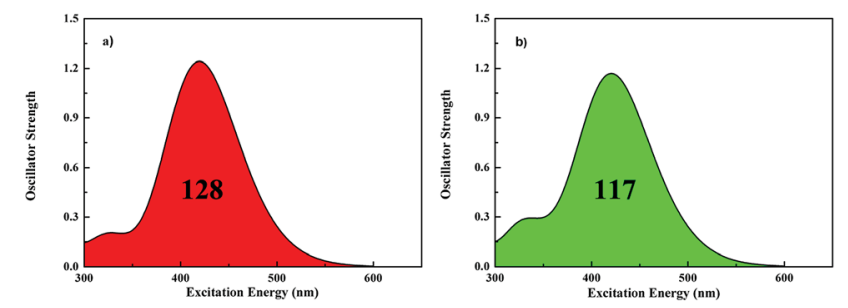

Fig. 2 Simulated absorption spectra for dye1 (a) and dye2 (b) in $\mathrm{CH}_{2} \mathrm{Cl}_{2}$ solution (128 and 117 represent the area of absorption bands for dye1 and dye 2 in the whole UV-vis region, respectively). 
Table 3 The excitation energies $\left(\lambda_{\max } / \mathrm{nm}\right)$, oscillator strengths ( $f$, and compositions of the lowest state for dye1 and dye2 (H: HOMO; L: LUMO)

\begin{tabular}{llllll}
\hline & & & & $\lambda_{\max }$ \\
& State & Composition $(\%)$ & $\lambda_{\max }$ & $f$ & 4 with molar absorption coefficient) \\
\hline dye1 & $\mathrm{S}_{0} \rightarrow \mathrm{S}_{1}$ & $\mathrm{H} \rightarrow \mathrm{L}(82.5), \mathrm{H}-1 \rightarrow \mathrm{L}(11.8)$ & 420 & 1.222 & $442(15100)$ \\
dye2 & $\mathrm{S}_{0} \rightarrow \mathrm{S}_{1}$ & $\mathrm{H} \rightarrow \mathrm{L}(81.6), \mathrm{H}-1 \rightarrow \mathrm{L}(11.7)$ & 421 & 1.117 & $448(16200)$
\end{tabular}

Table 4 Calculated redox potential, excitation energy $\lambda_{\max }$ and $D_{f}$ (in $\mathrm{eV}$ ), dipole moment $\mu_{\text {normal }}$ (in Debye) and number of electron injection $\Delta q$ (in e) of dye1 and dye2

\begin{tabular}{lllllll}
\hline & $E_{\text {dye }}$ & $\lambda_{\max }$ & $E^{\text {dye* }}$ & $D_{\mathrm{f}}$ & $\mu_{\text {normal }}$ & $\Delta q$ \\
\hline dye1 & -5.07 & 2.95 & -2.21 & 1.88 & 2.68 & 0.129 \\
dye2 & -5.27 & 2.95 & -2.32 & 1.68 & 4.71 & 0.107 \\
& & & & & &
\end{tabular}

adsorb dyes for the interface investigation. To model the $\mathrm{TiO}_{2}$ nanoparticle surface, we considered a $\left(\mathrm{TiO}_{2}\right)_{38}$ cluster, obtained by appropriately "cutting" from anatase slab exposing the majority (llll 1001 ) surface. ${ }^{47}$ The considered model represents a reasonable tradeoff between accuracy and computational convenience, and nicely reproduces the main electronic characteristics of $\mathrm{TiO}_{2}$ nanoparticles. We obtained HOMO-LUMO gap of $4.13 \mathrm{eV}$, while the TD-DFT lowest excitation energy of $3.63 \mathrm{eV}$ is in agreement with the experimental spectrometric measurement. For the studied $\left(\mathrm{TiO}_{2}\right)_{38}$ (101) model, the occupied MO can be attributed the contribution of $2 \mathrm{p}$ orbitals character of $\mathrm{O}$ atoms. While, the unoccupied MO can be attributed from the contribution of $3 \mathrm{~d}$ orbitals of $\mathrm{Ti}$ atoms. These characters are in agreement with that of the understanding in $\mathrm{TiO}_{2}$ semiconductor material. Though HOMOLUMO gap for this model is extended than the experimental band gap of crystal $(3.2-3.3 \mathrm{eV}),{ }^{31}$ it corresponds well with previously calculated HOMO-LUMO gaps for other $\left(\mathrm{TiO}_{2}\right)_{38}$ clusters. ${ }^{4-50}$ We used the plane-wave DFT to optimize the ground-state geometry of the $\left(\mathrm{TiO}_{2}\right)_{38}$ cluster and dye/( $\left.\mathrm{TiO}_{2}\right)_{38}$ complex. The electronic structure and related results of the $\left(\mathrm{TiO}_{2}\right)_{38}$ (101) model is reasonable and reliable for describing the conduction band properties of $\mathrm{TiO}_{2}$ semiconductor based on the both of accuracy and computational cost consideration.

In dye/ $\mathrm{TiO}_{2}$ adsorption model, organic dyes adsorbed on the $\mathrm{TiO}_{2}$ surface through the carboxylic group with several adsorption configurations owing to molecular or dissociative adsorption processes. The molecular adsorption is formed via hydrogen bonding between $\mathrm{TiO}_{2}$ surface and the dye. When the dissociative adsorption happens ( $\mathrm{H}$ atom of carboxylic acid dissociates), the bond is formed between carboxylic oxygen atoms and the surface titanium of $\mathrm{TiO}_{2}$, which can be monodentate ester, bidentate chelating, and bidentate bridging types. ${ }^{51,52}$ However, Fourier-transform infrared spectroscopy (FTIR) results for organic systems in many experimental studies indicate that carboxylic acid usually adsorbs on $\mathrm{TiO}_{2}$ surface through bidentate bridging structure, which was most studied in the literature and was thought to be the most stable. ${ }^{52-54}$ Therefore, only bidentate bridging adsorption was considered in current study. This adopted $\mathrm{TiO}_{2}$ model well described the interface charge transfer and the most important thing is that the adsorbed dye on $\mathrm{TiO}_{2}$ via its carboxylate group in a bidentate bridging manner, with one proton transferred to a nearby surface oxygen has been proved to be the most stable adsorption mode for this anchoring group.

The optimized structures of dye/ $\mathrm{TiO}_{2}$ complexes are shown in Fig. 3, and the important bond lengths and adsorption energies are listed in Table 3. The adsorption energy of dye1, calculated to be $22.9 \mathrm{kcal} \mathrm{mol}^{-1}$, is larger than that of dye2 $\left(21.4 \mathrm{kcal} \mathrm{mol}^{-1}\right)$ and both of them are large enough to allow the dyes to be adsorbed on the cluster in the chemical way. The bond lengths between $\mathrm{Ti}$ atoms and the carboxylic oxygen atoms were calculated to be 2.061 and $2.079 \AA$ for dye1, 2.035 and $2.108 \AA$ for dye2, respectively. The average $\mathrm{Ti}-\mathrm{O}$ bond length of dye1/ $/ \mathrm{TiO}_{2}$ is slightly shorter than that of dye2/ $/ \mathrm{TiO}_{2}$, indicating somewhat stronger binding of dye1 with $\mathrm{TiO}_{2}$ cluster. Intuitively, one can indeed expect a stronger electronic coupling in the dye1/ $/ \mathrm{TiO}_{2}$ system rather than dye $2 / \mathrm{TiO}_{2}$ system (Table 5 ).

In the most of important excitations (in Table 3), the LUMO shows considerable involvement and has largest contribution at largest adsorption energy $\lambda_{\max }$. Hence, the electronic coupling between the dye's LUMO and $\mathrm{TiO}_{2}$ conduction band is important for electron injection from the former to the latter. To gain insight into the electronic coupling between the dye's LUMO and $\mathrm{TiO}_{2}$ conduction band and the electron-transfer features during photo excitation, the frontier molecular orbitals (FMO) of dye/TiO ${ }_{2}$ system were analyzed. HOMO, LUMO, and the interacting orbitals for dye1/ $\mathrm{TiO}_{2}$ are shown in Fig. 4. The HOMO is localized on dye part of the complex as can be seen from Fig. 4(a), which is characteristically similar to that of the isolated dye. While, the LUMO is entirely localized on $\mathrm{TiO}_{2}$ part

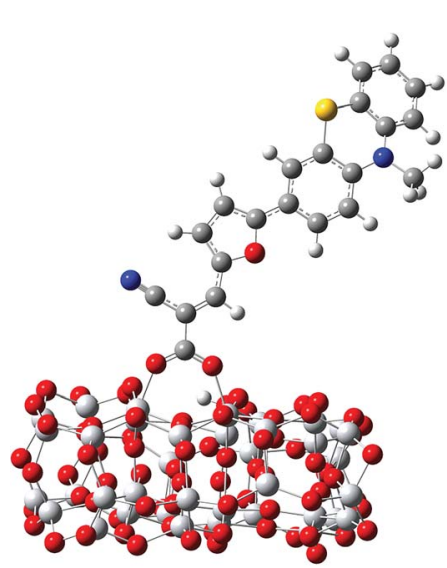

dye $1 / \mathrm{TiO}_{2}$

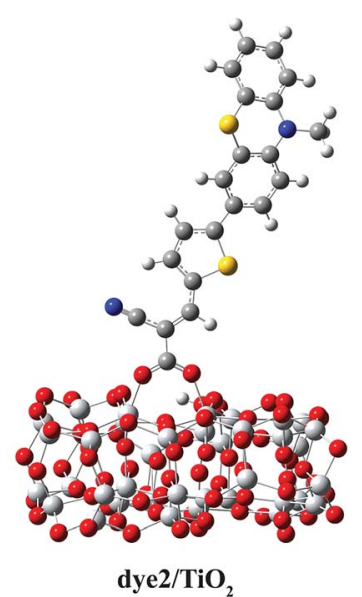

dye $2 / \mathrm{TiO}_{2}$
Fig. 3 Optimized structures of dye1 and dye2 adsorbed on $\mathrm{TiO}_{2}$ surface. 
Table 5 Optimized bond lengths (in angstrom) and adsorption energy (in kcal $\mathrm{mol}^{-1}$ ) of dye1/TiO 2 and dye $2 / \mathrm{TiO}_{2}$

\begin{tabular}{llll}
\hline & O-Ti $(1)$ & O-Ti $(2)$ & $E_{\text {ads }}$ \\
\hline dye1 $/ \mathrm{TiO}_{2}$ & 2.061 & 2.079 & 22.9 \\
dye2/ $/ \mathrm{TiO}_{2}$ & 2.035 & 2.108 & 21.4
\end{tabular}

of the complex (Fig. 4(b)). The interacting LUMOs that have non-negligible contributions from the isolated free dye's LUMO are situated higher up in the conduction band (LUMO + 49). For dye $2 / \mathrm{TiO}_{2}$ system, the FMOs features are similar to those of the dye1/ $/ \mathrm{TiO}_{2}$ system. In DSSCs, the efficient electrons are transferred from donor through $\pi$-bridge to cyanoacrylate. Based on this, the spatial orientation of the FMOs for the isolated dye (shown in Fig. 5) and the dye/ $\mathrm{TiO}_{2}$ interface here (shown in Fig. 4) are ideal conditions for DSSCs. Fig. 6 shows the density of states for dye1 and dye2 before and after adsorbing on $\mathrm{TiO}_{2}$ surface. From which we find that the HOMO of both dyes are almost unaffected by interaction with $\mathrm{TiO}_{2}$, showing the alignment of the energy levels as in the no-interacting case. The obvious difference between the isolated and interacting systems is in the shape and distribution of the LUMOs. Both of LUMOs of dyes adsorbed on $\mathrm{TiO}_{2}$ surface decrease due to the interaction with $\mathrm{TiO}_{2}$ semiconductor, and this is in agreement with previous reports of the perylene dye and $\mathrm{TiO}_{2}$ cluster. ${ }^{55}$ For dye1, the LUMO is $0.25 \mathrm{eV}$ lower after absorbing on the $\mathrm{TiO}_{2}$ surface. While for dye2, the decrease of LUMO is calculated to be $0.23 \mathrm{eV}$, indicating slightly weaker electronic coupling to $\mathrm{TiO}_{2}$ surface than dye1. In case of similar molecular geometry when anchored to $\mathrm{TiO}_{2}$, the large stabilization to the LUMO will enhance the electronic coupling between the dye and the titanium $3 \mathrm{~d}$ orbitals and favor the electron injection. The charge transfer states with direct charge injection character are performed by TD-DFT, and the results indicate that the absorption transitions of both adsorbed systems are bathochromic shifted near $500 \mathrm{~nm}$, and the dye1/ $\mathrm{TiO}_{2}$ is increasing $40 \mathrm{~nm}$ towards longer wavelength with higher intensity (oscillator strength 0.98 vs. 0.82 ) in contrast with dye $2 / \mathrm{TiO}_{2}$. These results are also in concert with previous adsorption energy and binding strength values.

Through eqn (5), the different dipole is expected to substantially influence the $E_{\mathrm{CB}}$ of $\mathrm{TiO}_{2}$, which will lead to a change in open-circuit photovoltage $V_{\text {oc }}$. Grätzel and
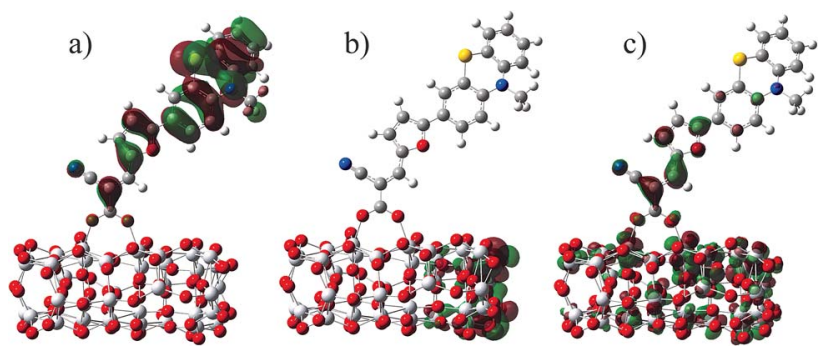

Fig. 4 Some selected MO profiles for the HOMO (a), LUMO (b) and interaction orbital (c) of dye1/ $\mathrm{TiO}_{2}$.

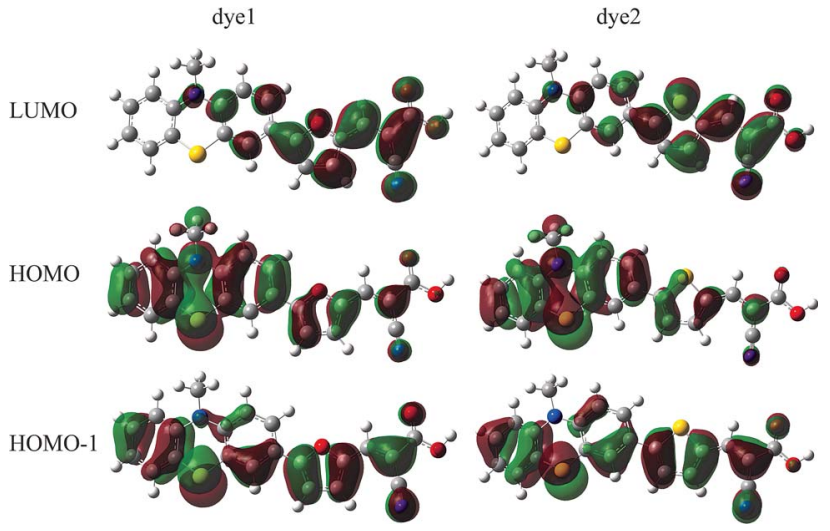

Fig. 5 Selected Frontier molecular orbitals at ground state of dye1 and dye2.

coworkers have confirmed theoretically that the larger the dipole moment $\mu_{\text {normal }}$ of the adsorbed molecules pointing outward from the semiconductor surface induced the larger $V_{\text {oc }}{ }^{56}$ Accordingly, $\mu_{\text {normal }}$ of both dyes were calculated under B3LYP/6-31G(d) level including solvent effects at the geometry of dyes adsorbed on $\mathrm{TiO}_{2}$ and the results are listed in Table 4. It turns out that dye 2 has much larger $\mu_{\text {normal }}$ than dye1, thus it can be inferred that dye2 should have larger $V_{\text {oc }}$ than dye1. But this is not in line with the experiment results (734.6 and $706.6 \mathrm{mV}$ for dye1 and dye2, respectively). ${ }^{24}$ According to eqn (4), we know that $V_{\text {oc }}$ also depends on the charge distribution in the semiconductor. As a result, we calculated the number of charge injected into the $\mathrm{TiO}_{2}$ conduction band $\Delta q$ by means of natural population analysis (NPA) and the results are listed in Table 4 . Dye1 has a larger $\Delta q$ than dye2 $(0.129 e>0.107 e)$, which could shift the quasi-Fermi level of $\mathrm{TiO}_{2}$ accordingly, then lead to larger $V_{\mathrm{oc}}$. Therefore, we believe that the larger experimental $V_{\text {oc }}$ of dye1 is mostly ascribed to the more electrons transferred from dye1 to $\mathrm{TiO}_{2}$. Although the difference in $V_{\text {oc }}$ for dye1 and dye 2 has been demonstrated, it needs to be pointed out that the $V_{\text {oc }}$ is also determined by other factors, such as electron lifetime. The relevant study is underway in our following work.

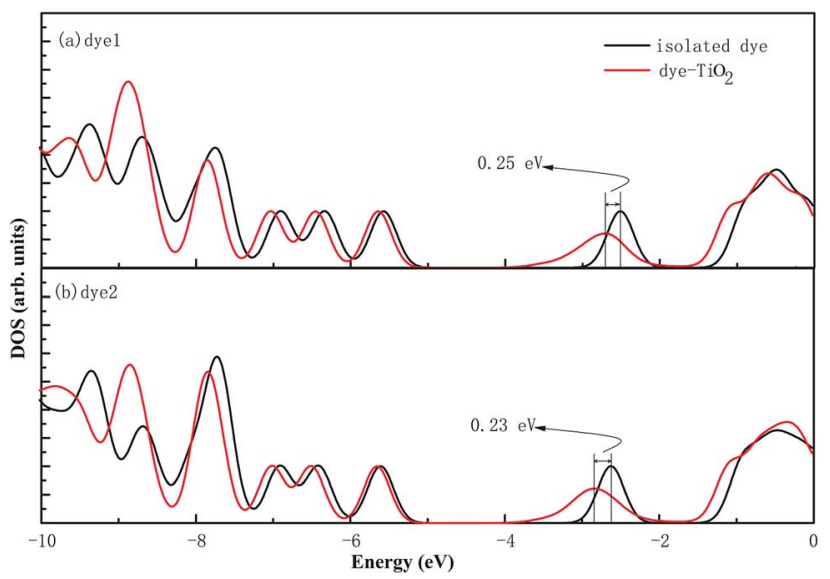

Fig. 6 The density of states of dye1 and dye2 before and after adsorbed on the $\mathrm{TiO}_{2}$ surface. 


\section{Conclusion}

In summary, the geometries, electronic structures, absorption spectrum of two PTZ dyes with different $\pi$-bridges were investigated to gain insights into the effects of the $\pi$-bridge group of furan and thiophene on the performance of the dyes. The electrons in furan-containing dye could be more easily transferred from PTZ-donor to acceptor than that in thiophenecontaining one due to the shorter bridge bonds and the flatter structure. After adsorption to the $\mathrm{TiO}_{2}$ cluster, as compared with dye2, dye1 shows a stronger coupling with the $\mathrm{TiO}_{2}$. dye1 with furan shows intrinsic enhanced short-circuit photocurrent density $J_{\mathrm{sc}}$ than dye2 with thiophene because it has larger driving force and comparable light harvesting efficiency, and the more electrons transferred from dye1 to $\mathrm{TiO}_{2}$ surface lead to larger open-circuit photovoltage $V_{\text {oc }}$. Our results indicate that furan could be used as a promising $\pi$-bridge to improve the efficiency of PTZ dyes. We also hope our work will be helpful for designing more efficient PTZ dyes in DSSCs with reduced economical cost and synthesis effort.

\section{Conflicts of interest}

There are no conflicts to declare.

\section{Acknowledgements}

This work was supported by the Natural Science Foundation of China (Grant No. 21573088 and 21203071) and the Jilin Provincial Natural Science Foundation (Grant No. 201215031) and Young Scholar Training Program of Jilin University.

\section{Notes and references}

1 M. Grätzel, Acc. Chem. Res., 2009, 42, 1788-1798.

2 A. Hagfeldt, G. Boschloo, L. Sun, L. Kloo and H. Pettersson, Chem. Rev., 2010, 110, 6595-6663.

3 M. Xie, J. Wang, H.-Q. Xia, F.-Q. Bai, R. Jia, J.-G. Rim and H.-X. Zhang, RSC Adv., 2015, 5, 33653-33665.

4 M. K. Nazeeruddin, A. Kay, I. Rodicio, R. Humphry-Baker, E. Mueller, P. Liska, N. Vlachopoulos and M. Grätzel, J. Am. Chem. Soc., 1993, 115, 6382-6390.

5 C.-Y. Chen, S.-J. Wu, C.-G. Wu, J.-G. Chen and K.-C. Ho, Angew. Chem., 2006, 118, 5954-5957.

6 L.-J. He, J. Chen, F.-Q. Bai, R. Jia, J. Wang and H.-X. Zhang, RSC Adv., 2016, 6, 81976-81982.

7 L.-L. Li and E. W.-G. Diau, Chem. Soc. Rev., 2013, 42, 291-304.

8 K. Hara, M. Kurashige, S. Ito, A. Shinpo, S. Suga, K. Sayama and H. Arakawa, Chem. Commun., 2003, 252-253.

9 K. Hara, T. Sato, R. Katoh, A. Furube, T. Yoshihara, M. Murai, M. Kurashige, S. Ito, A. Shinpo, S. Suga and H. Arakawa, Adv. Funct. Mater., 2005, 15, 246-252.

10 S. Ito, S. M. Zakeeruddin, R. Humphry-Baker, P. Liska, R. Charvet, P. Comte, M. K. Nazeeruddin, P. Pechy, M. Takata, H. Miura, S. Uchida and M. Grätzel, Adv. Mater., 2006, 18, 1202-1205.
11 D. P. Hagberg, J.-H. Yum, H. Lee, F. De Angelis, T. Marinado, K. M. Karlsson, R. Humphry-Baker, L. Sun, A. Hagfeldt, M. Grätzel and M. K. Nazeeruddin, J. Am. Chem. Soc., 2008, 130, 6259-6266.

12 W. Zhu, Y. Wu, S. Wang, W. Li, X. Li, J. Chen, Z.-S. Wang and H. Tian, Adv. Funct. Mater., 2011, 21, 756-763.

13 M. Xie, J. Wang, F.-Q. Bai, L. Hao and H.-X. Zhang, Dyes Pigm., 2015, 120, 74-84.

14 M. K. Nazeeruddin, F. De Angelis, S. Fantacci, A. Selloni, G. Viscardi, P. Liska, S. Ito, B. Takeru and M. Grätzel, J. Am. Chem. Soc., 2005, 127, 16835-16847.

15 C. Xie, P. You, Z. Liu, L. Li and F. Yan, Light: Sci. Appl., 2017, 6, e17023.

16 A. Mishra, M. K. R. Fischer and P. Bäuerle, Angew. Chem., Int. Ed., 2009, 48, 2474-2499.

17 K. Hara, M. Kurashige, Y. Dan-oh, C. Kasada, A. Shinpo, S. Suga, K. Sayama and H. Arakawa, New J. Chem., 2003, 27, 783-785.

18 C. Chen, X. Yang, M. Cheng, F. Zhang, J.-H. Zhao and L. Sun, ACS Appl. Mater. Interfaces, 2013, 5, 10960-10965.

19 B. Park, S. H. Yun, C. Y. Cho, Y. C. Kim, J. C. Shin, H. G. Jeon, Y. H. Huh, I. Hwang, K. Y. Baik, Y. I. Lee, H. S. Uhm, G. S. Cho and E. H. Choi, Light: Sci. Appl., 2014, 3, e222.

20 Z. S. Wang, Y. Cui, Y. Dan-oh, C. Kasada, A. Shinpo and K. Hara, J. Phys. Chem. C, 2008, 112, 17011-17017.

21 R. Katoh, A. Furube, S. Mori, M. Miyashita, K. Sunahara, N. Koumura and K. Hara, Energy Environ. Sci., 2009, 2, 542-546.

22 W. H. Zhu, Y. Z. Wu, S. T. Wang, W. Q. Li, X. Li, J. Chen, Z. S. Wang and H. Tian, Adv. Funct. Mater., 2011, 21, 756-763. 23 U. H. F. Bunz, Angew. Chem., Int. Ed., 2010, 49, 5037-5040.

24 S. H. Kim, H. W. Kim, C. Sakong, J. Namgoong, S. W. Park, M. J. Ko, C. H. Lee, W. I. Lee and J. P. Kim, Org. Lett., 2011, 13, 5784-5787.

25 S. Qu, B. Wang, F. Guo, J. Li, W. Wu, C. Kong, Y. Long and J. Hua, Dyes Pigm., 2012, 92, 1384-1393.

26 J. Zhang, H. B. Li, S. L. Sun, Y. Geng, Y. Wu and Z.-M. Su, J. Mater. Chem., 2012, 22, 568-576.

27 D. Kuciauskas, J. E. Monat, R. Villahermosa, H. B. Gray, N. S. Lewis and J. K. McCusker, J. Phys. Chem. B, 2002, 106, 9347-9358.

28 J. Wang, F. Q. Bai, B. H. Xia, L. Feng, H. X. Zhang and Q. J. Pan, Phys. Chem. Chem. Phys., 2011, 13, 2206-2213.

29 R. Katoh, A. Furube, T. Yoshihara, K. Hara, G. Fujihashi, S. Takano, S. Murata, H. Arakawa and M. Tachiya, J. Phys. Chem. B, 2004, 108, 4818-4822.

30 J. Feng, Y. Jiao, W. Ma, M. K. Nazeeruddin, M. Grätzel and S. Meng, J. Phys. Chem. C, 2013, 117, 3772-3778.

31 M. Khoudiakov, A. R. Parise and B. S. Brunschwig, J. Am. Chem. Soc., 2003, 125, 4637-4642.

32 T. Marinado, K. Nonomura, J. Nissfolk, M. K. Karlsson, D. P. Hagberg, L. Sun, S. Mori and A. Hagfeldt, Langmuir, 2009, 26, 2592-2598.

33 S. Rühle, M. Greenshtein, S. G. Chen, A. Merson, H. Pizem, C. S. Sukenik, D. Cahen and A. Zaban, J. Phys. Chem. B, 2005, 109, 18907-18913. 
34 C. Lee, W. Yang and R. G. Parr, Phys. Rev. B, 1988, 37, 785789.

35 T. Yanai, D. P. Tew and N. C. Handy, Chem. Phys. Lett., 2004, 393, 51-57.

36 C. Adamo and V. Barone, J. Chem. Phys., 1999, 110, 6158.

37 A. D. Becke, J. Chem. Phys., 1993, 98, 1372-1377.

38 Y. Zhao and D. G. Truhlar, Theor. Chem. Acc., 2008, 120, 215241.

39 G. Kresse and J. Hafner, Phys. Rev. B, 1993, 47, 558-561.

40 G. Kresse and J. Furthmüller, Comput. Mater. Sci., 1996, 6, 15-50.

41 J. P. Perdew, K. Burke and M. Ernzerhof, Phys. Rev. Lett., 1996, 77, 3865-3868.

42 G. W. T. M. J. Frisch, H. B. Schlegel, G. E. Scuseria, M. A. Robb, J. R. Cheeseman, G. Scalmani, V. Barone, B. Mennucci, G. A. Petersson, H. Nakatsuji, M. Caricato, X. Li, H. P. Hratchian, A. F. Izmaylov, J. Bloino, G. Zheng, J. L. Sonnenberg, M. Hada, M. Ehara, K. Toyota, R. Fukuda, J. Hasegawa, M. Ishida, T. Nakajima, Y. Honda, O. Kitao, H. Nakai, T. Vreven, J. A. Montgomery Jr., J. E. Peralta, F. Ogliaro, M. Bearpark, J. J. Heyd, E. Brothers, K. N. Kudin, V. N. Staroverov, R. Kobayashi, J. Normand, K. Raghavachari, A. Rendell, J. C. Burant, S. S. Iyengar, J. Tomasi, M. Cossi, N. Rega, J. M. Millam, M. Klene, J. E. Knox, J. B. Cross, V. Bakken, C. Adamo, J. Jaramillo, R. Gomperts, R. E. Stratmann, O. Yazyev, A. J. Austin, R. Cammi, C. Pomelli, J. W. Ochterski, R. L. Martin, K. Morokuma, V. G. Zakrzewski, G. A. Voth, P. Salvador, J. J. Dannenberg, S. Dapprich, A. D. Daniels, O. Farkas, J. B. Foresman, J. V. Ortiz, J. Cioslowski, and D. J. Fox, Gaussian 09, Revision D.01, Gaussian, Inc., Wallingford CT, 2009.
43 C. Teng, X. Yang, C. Yang, H. Tian, S. Li, X. Wang, A. Hagfeldt and L. Sun, J. Phys. Chem. C, 2010, 114, 11305-11313.

44 H. Chen, H. Huang, X. Huang, J. N. Clifrord, A. Forneli, E. Palomares, X. Zheng, L. Zheng, X. Wang, P. Shen, B. Zhao and S. Tan, J. Phys. Chem. C, 2010, 114, 3280-3286.

45 F. Li, Y.-Z. Zhu, S.-C. Zhang, H.-H. Gao, B. Pan and J.-Y. Zheng, Dyes Pigm., 2017, 139, 292-299.

46 A. F. Buene, N. Uggerud, S. P. Economopoulos, O. R. Gautun and B. H. Hoff, Dyes Pigm., 2018, 151, 263-271.

47 M. J. Lundqvist, M. Nilsing, P. Persson and S. Lunell, Int. J. Quantum Chem., 2006, 106, 3214-3234.

48 S. Agrawal, P. Dev, N. J. English, K. R. Thampi and J. M. D. MacElroy, Chem. Sci., 2012, 3, 416.

49 S. Agrawal, P. Dev, N. J. English, K. R. Thampi and J. M. D. MacElroy, J. Mater. Chem., 2011, 21, 11101.

50 W. Li, F.-Q. Bai, J. Chen, J. Wang and H.-X. Zhang, J. Power Sources, 2015, 275, 207-216.

51 A. Vittadini, A. Selloni, F. P. Rotzinger and M. Grätzel, J. Phys. Chem. B, 2000, 104, 1300-1306.

52 M. K. Nazeeruddin, R. Humphry-Baker, P. Liska and M. Gratzel, J. Phys. Chem. B, 2003, 107, 8981-8987.

53 K. Srinivas, K. Yesudas, K. Bhanuprakash, V. J. Rao and L. Giribabu, J. Phys. Chem. C, 2009, 113, 20117-20126.

54 K. Hara, T. Sato, R. Katoh, A. Furube, Y. Ohga, A. Shinpo, S. Suga, K. Sayama, H. Sugihara and H. Arakawa, J. Phys. Chem. B, 2003, 107, 597-606.

55 F. De Angelis, Chem. Phys. Lett., 2010, 493, 323-327.

56 P. Chen, J. H. Yum, F. D. Angelis, E. Mosconi, S. Fantacci, S.-J. Moon, R. H. Baker, J. Ko, M. K. Nazeeruddin and M. Grätzel, Nano Lett., 2009, 9, 2487-2492. 